\title{
Influence of p53 on anti-tumor immunity (Review)
}

\author{
MARCO BUETER $^{1}$, MARTIN GASSER $^{1}$, TATIANA LEBEDEVA ${ }^{2}$, \\ GILLES BENICHOU $^{3}$ and ANA MARIA WAAGA-GASSER ${ }^{1}$
}

\author{
${ }^{1}$ Department of Surgery I, Molecular Oncology and Immunology, University of Wuerzburg, D-97080 Wuerzburg, Germany; \\ ${ }^{2}$ American Red Cross, New England Region, Dedham, MA 02026; ${ }^{3}$ Department of Surgery, Transplantation Unit, \\ Massachusetts General Hospital, Harvard Medical School, Boston, MA 02114, USA
}

Received August 5, 2005; Accepted September 16, 2005

\begin{abstract}
Self-tolerance and tumor-induced peripheral tolerance may be responsible for the limitations of the immune system in controlling tumor growth in cancer patients. It is known, that self-proteins are continuously processed and presented by antigen presenting cells. During development, auto-reactive $\mathrm{T}$ cells encountering self peptide/self-MHC complexes are being eliminated in the thymus. This process called 'negative selection' results in the removal of nascent auto-reactive $\mathrm{T}$ cells thus preventing an autoimmune attack of our own tissues. Many self-peptides (e.g. parts of p53), despite their high affinity for self-MHC, remain cryptic in the thymus and do not mediate cell deletion. Under conditions that favor up-regulation of cryptic self-determinants, one or more of these subsets of the 'protected' $\mathrm{T}$ cell repertoires, can be stimulated by these self-determinants, leading to induction of autoreactivity. The latter could eventually result in autoimmunity under permissive conditions governed by MHC and non-MHC genes. Thus, considering tumor tissue a 'modified self-tissue', this process that may have evolved to prevent excessive purge of the $\mathrm{T}$ cell repertoire, providing the potential for the development of autoimmune responses and therefore for anti-cancer therapy in adults.
\end{abstract}

Correspondence to: Professor Ana Maria Waaga-Gasser, Department of Surgery I, Molecular Oncology and Immunology, University of Wuerzburg, Zentrum Operative Medizin, Oberduerrbacher Str. 6, D-97080 Wuerzburg, Germany

E-mail: waaga-gasser@chirurgie.uni-wuerzburg.de

Abbreviations: APC, antigen presenting cells; MHC, major histocompatibility complex; HLA, human leukocyte antigen; CTL, cytotoxic T-lymphocytes; Th1, T helper cells type 1; Th2, T helper cells type 2

Key words: p53, target immunotherapy, type 1 and $2 \mathrm{~T}$ cell responses, cryptic self-determinants

\section{Contents}

1. Introduction

2. p53 protein as a 'guardian of the genome'

3. Regulation of the immune response: the role of type 1 versus type $2 \mathrm{~T}$ cell responses

4. The immunogenicity of p53 protein

5. p53 - a suitable target for immunotherapy approaches?

6. Immunogenicity and tolerogenicity of tumor antigens: role of dominant and cryptic self-determinants

7. Dominant and cryptic determinants of the p53 protein

8. Conclusions

\section{Introduction}

The identification of tumor antigens has contributed to the development of cancer vaccines and to a better understanding of the immune response to cancer cells (1). Tumor antigens can be either tumor-specific, found in tumor-tissue only, or tumor-associated, present in normal tissue but highly overexpressed in tumors (2-8). Tumor antigens are regularly processed and presented on the cell surface by human leukocyte antigen (HLA) class I molecules. The emerging HLApeptide complexes are under a permanent surveillance of the immune system (9). While CD4 ${ }^{+} \mathrm{T}$ helper cells are restricted to major histocompatibility complex (MHC) class II molecules, cytotoxic $\mathrm{CD}^{+} \mathrm{T}$ cells recognize peptides presented by HLA class I molecules (10). Most of the studies have been focused on cytotoxic T-lymphocytes (CTLs) and the presentation of tumor peptides by MHC class I molecules. In turn, few studies have addressed the contribution of anti-tumor-specific $\mathrm{CD}^{+}{ }^{+}$ $\mathrm{T}$ cells in cancer.

During the last decades several tumor antigen epitopes have been identified, including p53, RAS or carcinoembryonic antigen (CEA) (11). Most of them are recognized by $\mathrm{CD}^{+}$ $\mathrm{T}$ cells (12). The fact that approximately $50 \%$ of all human malignancies exhibit mutation and aberrant expression of $\mathrm{p} 53$, makes this tumor suppressor gene an attractive target for cancer immunotherapy. This review focuses on the most recently elucidated mechanisms involved in the initiation and modulation of $\mathrm{T}$ cell-mediated immunity and the processing and presentation of antigens. The impact of this valuable information on studies directed to understand tumor immunity 
and the feasibility of p53 specific immunotherapy in human malignancies will be discussed.

\section{2. p53 protein as a 'guardian of the genome'}

Wild-type p53 protein acts as a regulator of the cell cycle (13). In response to DNA damage, p53 accumulates in cell nuclei causing cell arrest at the G1 phase. Thus, p53 represents a 'guardian of the genome' as it prohibits the occurrence of genetic aberrations preventing the expansion of abnormal, tumorigenic cells $(14,15)$. In cancer cells, p53 function is impaired by either gene mutation or binding of viral or cellular oncogene-derived proteins. Following p53 modification, genetic alterations rapidly accumulate, a phenomenon leading to malignant transformation and tumor formation. The frequency of p53 gene mutations is elevated in colon, stomach, breast, and lung cancer, as well as in leukemia, osteosarcoma, ovarian cancer, and brain tumors (16). Altogether, p53 gene alterations are present in about $50 \%$ of all cancer patients, which makes it a very attractive target for new combined oncologic and immunologic therapeutic approaches.

\section{Regulation of the immune response: the role of type 1 versus type $2 \mathrm{~T}$ cell responses}

The immune system is designed to ensure immune destruction of foreign components (bacteria, fungus, viruses, etc.) while avoiding immune reactions directed towards autologous components. $\mathrm{CD}^{+}{ }^{+} \mathrm{T}$ cell-mediated immune responses can be divided into two main categories: i) the type $1 \mathrm{~T}$ cell response mediated by $\mathrm{CD}^{+} \mathrm{T}$ helper cells type 1 (Th1) which secrete IL-2 and IFN- $\gamma$ following antigen stimulation, and ii) the type 2 $\mathrm{T}$ cell response mediated by $\mathrm{CD}^{+} \mathrm{T}$ helper cells type 2 (Th2) which secrete IL-4, IL-5 and IL-10 (17,18). Type 1 and $2 \mathrm{~T}$ cells differ in their specificity to peptide determinants, in their susceptibility to antigen stimulation, and in their dependency on costimulatory signals delivered by antigen presenting cells (APCs) (19). Several studies have shown that these two subsets of $\mathrm{T}$ cell responses mediate not only different immune functions but that type 1 and $2 \mathrm{~T}$ cell responses act antagonistically. Thus, factors which promote type $1 \mathrm{~T}$ cell responses also prevent type 2 responses while factors driving the $\mathrm{T}$ cell response to a type 2 phenotype inhibit type $1 \mathrm{~T}$ cell responses. This phenomenon of bipolarity plays a critical role in regulating immune responses in vivo. It has been shown that inflammatory Th1 responses are mainly involved in maintaining immune protection by rejecting foreign components such as microbes or transplanted tissues. In contrast, Th2 responses are implicated in immune tolerance towards self-components (20).

\section{The immunogenicity of $\mathbf{p 5 3}$ protein}

In normal cells, p53 protein is present at extremely low levels and exclusively in the nucleus. This is largely due to the fact that newly synthesized wild-type p53 is highly sensitive to ubiquitin/proteasome-mediated degradation via the MDM2 pathway (21). Despite the fact that the p53 antigen is expressed in the developing thymus and can mediate negative selection of anti-p53 reactive $\mathrm{CD} 8^{+} \mathrm{T}$ cells, the complete deletion of
$\mathrm{CD}^{+} \mathrm{T}$ cells specific for self-p53 protein is not achieved $(22,23)$. Consequently, the organism retains the potential of developing an anti-p53-immune response as p53 becomes available for presentation as an auto-antigen. Furthermore, wild-type p53 is not presented on the surface of parenchymal cells in adults, making the protein in healthy humans invisible or cryptic for the immune system $(24,25)$. High cytoplasmic levels of p53 in cancer cells may represent a source of protein for antigen processing and presentation on the surface of malignant cells for recognition by $\mathrm{T}$ cells via proteasome processing (MHC class I restricted). Moreover, large amounts of mutated p53 is released by necrotic parts of the expanding tumor and can be uptaken, processed and then presented and cross-presented by professional APCs (MHC class II and class I restricted). Fedoseyeva et al analyzed MHC class IIrestricted $\mathrm{CD}^{+} \mathrm{T}$ cell responses to wild-type and mutant $\mathrm{p} 53$ in healthy and tumor-bearing mice. They demonstrated that anti-p53 T cells specific to certain wild-type p53 determinants were present in the periphery of the adult immune system and could be specifically activated after p53 peptide immunization. These mice mounted potent $\mathrm{CD}^{+} \mathrm{T}$ cell responses to $\mathrm{p} 53$ and this response was mediated by $\mathrm{T}$ cells recognizing the mutated portion of p53 and by $\mathrm{T}$ cells directed to formerly cryptic self-p53 determinants. Furthermore, they observed that the anti-p53 Th response was directed towards distinct p53 peptides depending upon the stage of tumorigenesis (26). Thus, although wild-type p53 in normal cells is ignored by the immune system, the presence of the new determinants derived from the processing of mutant p53 cancer-associated protein may result in $\mathrm{T}$ cell-mediated immune responses and presumably in tumor elimination. This scenario may include p53 epitopes derived from mutated and non-mutated parts of the protein that could be used for anti-tumor vaccination protocols. The so-called 'cryptic regions' of the wild-type protein that are usually not presented in the thymus may elicit a specific anti-tumor response and may be also suitable to generate a specific $\mathrm{T}$ cell-mediated immune response.

\section{5. p53 - a suitable target for immunotherapy approaches?}

Several in vivo studies have outlined the humoral and cellular immune responses to p53 in cancer patients as well as in mouse models $(27,28)$. Schlichtholz et al have demonstrated the presence of circulating antibodies against p53 protein in patients with breast carcinoma (29). These antibodies were predominantly associated with p53 gene missense mutations and p53 accumulation in the tumor. However, they were detected in only $30 \%$ of patients with malignancies. Detection of circulating anti-p53 antibodies has been associated with high-grade tumors and poor survival in breast, colon, and gastric cancer patients (30). There is accumulating evidence that these circulating antibodies could have promising potential in the early detection of cancer. However, in our recent studies of p53 auto-antibodies in sera of colorectal cancer patients using ELISA, only $26 \%$ of all tested patients expressed wildtype p53 specific-IgG-antibodies (11 out of 42) while no correlation was found between the UICC state, tumor differentiation, and p53 auto-antibody (Bueter et al, Proc ASCO 24: abs. 859, 2005). In fact, the existence of p53 autoantibodies showed no significant correlation with the size 
(T1-4) and grade (G1-3) of the primary tumor. The mechanisms that lead to the synthesis of anti-p53 auto-antibodies and the immunological relevance of such a response in vivo are still unknown. Much more is known about T cell-mediated responses to p53. Recently, different groups have shown that $\mathrm{CD}^{+}$and $\mathrm{CD}^{+} \mathrm{T}$ cell responses against $\mathrm{p} 53$ protein could be elicited in vivo following immunization in mice $(26,31)$ as well as in cancer patients. They demonstrated the presence of circulating p53 tumor-specific $\mathrm{CD}^{+} \mathrm{T}$ cells in patients with melanoma. However, these cytotoxic T-lymphocytes (CTLs) were unable to eliminate the tumor within these patients $(32,33)$.

Several vaccination studies have been undertaken using p53 peptides, either derived from the wild-type protein or in an engineered and modified form, in order to improve the HLA binding and subsequently to achieve a better epitope recognition by CTLs. In HLA-A2.1/K $\mathrm{K}^{\mathrm{b}}$ transgenic mice $\mathrm{CD} 8^{+}$ $\mathrm{T}$ cells specific for the murine $\mathrm{p} 53_{261-269}$ epitope expressed only TCRs with low affinity (33). This scenario, in which only a weak response comprised of relatively low-affinity $\mathrm{CD}^{+}$ $\mathrm{T}$ cells is available to respond against a tumor antigen, probably represents a common anti-tumor immune response for many tumor-associated epitopes. The authors tried to overcome this phenomenon by administration of anti-CTLA-4 monoclonal antibody. Although an increase of CTLs specific for the used p53 $261-269$ peptide was achieved, anti-CTLA-4 treatment did not enhance the avidity of this population and, therefore, the functional state of tolerance could not be reversed. This study demonstrates that tolerance to p53 self-protein in fact is not complete and can be overcome in vivo. However, anti-selfp53 responses seem to be too weak and not specific enough to efficiently eradicate p53 positive tumor cells indicating that not only a poor co-stimulation but also other mechanisms must be involved in this process resulting in the low affinity of CTLs. These effects counteract an efficient immune response against p53 and may lead rather to tolerance than rejection of the tumor. Alternative mechanisms resulting in this phenomenon could be the following: i) a very small amount of antigen available for presentation during tumor development may be insufficient to induce an anti-tumor immune response, as in cases with low doses of pathogens; ii) the individual peptides derived from the same protein may compete so that the final effect in vivo may be determined by the balance of the amounts of all presented peptides instead of just one single peptide.

However, the data highlight the potential role of $\mathrm{CD}^{+} \mathrm{T}$ helper cells either in inducing and maintaining or blocking and inhibiting anti-tumor immune responses. The fundamental questions that need to be addressed are: i) what are the determinants generated following the processing of $\mathrm{p} 53$ protein for presentation to $\mathrm{T}$ cells and ii) which determinants are decisive, upon presentation to $\mathrm{T}$ helper cells, for the resulting immune response (tolerance or rejection).

\section{Immunogenicity and tolerogenicity of tumor antigens: role of dominant and cryptic self-determinants}

Classically, lymphocyte tolerance mechanisms have been divided into two broad categories. Central tolerance $(34,35)$ concerns immature $\mathrm{T}$ or $\mathrm{B}$ cells as they differentiate in the primary lymphoid organs, the thymus or bone marrow. Relevant antigens, then, would be those synthesized by nurturing stromal cells, circulating hematopoietic cells, or, ubiquitously, by all cells. The major mechanisms that come into play during central tolerance appear to be clonal deletion or inactivation of self-reactive lymphocytes, the former in particular. Peripheral tolerance (36), on the other hand, relates to mature $\mathrm{T}$ or $\mathrm{B}$ cells after they have exited the primary lymphoid organs and are circulating through the blood, lymph, and secondary lymphoid organs or have accessed the parenchymal tissues in response to some stimulus. Antigens of concern would primarily be those expressed in the tissues and not in the thymus or bone marrow. Clonal deletion and anergy are tolerance mechanisms also employed in the periphery, but a variety of other means are also exploited, including clonal ignorance, deviation, helplessness, and suppression.

The relative significance of central versus peripheral tolerance has been debated for decades, with sequential waves of enthusiasm supporting either one or the other. Certainly, central mechanisms are important - for example, a variety of approaches have estimated that one-half to two-thirds of thymocytes that are positively selected subsequently undergo negative selection (37-39). However, central tolerance appears not to be reliable as all individuals harbor lymphocytes in the blood that can respond to self-antigens $(40,41)$. Therefore, peripheral mechanisms must be important as well. Indeed, over the past several years peripheral tolerance - in particular, the activities of regulatory T cells (42) - have held the limelight.

Self-tolerance and tumor-induced peripheral tolerance may be responsible for the limitations of the immune system in controlling tumor growth in cancer patients. Therefore, we can hypothesize that some tumor-reactive $\mathrm{T}$ cells may indeed be inactivated or eliminated during the process of the development of self-tolerance.

It is known, however, that self-proteins are continuously processed and presented by APCs. During development, autoreactive $\mathrm{T}$ cells encountering self peptide/self-MHC complexes are being eliminated in the thymus. This process called 'negative selection' results in the removal of nascent autoreactive $\mathrm{T}$ cells thus preventing an autoimmune attack of self tissues $(43,44)$. Many self-peptides (e.g. parts of p53), despite their high affinity for self-MHC, remain cryptic in the thymus and do not mediate cell deletion. Multiple factors have been implicated in crypticity: slow or incomplete availability of the determinant during unfolding of the protein molecules (indolent processing), an enzymatic destruction of the determinant (excessive processing) or the dominance of a flanking determinant that competes effectively for binding to the same MHC molecule (45). The total remaining after negative selection of self-reactive $\mathrm{T}$ cell repertoire directed against a single antigen will be a heterogeneous assemblage of $\mathrm{T}$ cells. This assemblage, for instance, can include high affinity $\mathrm{T}$ cells directed against determinants that were not presented during tolerance induction. This occurs through the competitive binding by neighboring determinants, when $\mathrm{T}$ cells directed against well-presented (dominant) as well as poorly-presented (cryptic) determinants have lower affinity, and when high affinity $\mathrm{T}$ cells are directed against poorly-presented determinants that are only presented during inflammation. 
Under conditions that favor up-regulation of cryptic selfdeterminants, one or more of these subsets of the 'protected' $\mathrm{T}$ cell repertoires can be stimulated by these self-determinants, leading to induction of autoreactivity. The latter could eventually result in autoimmunity under permissive conditions governed by MHC and non-MHC genes (46). Thus, considering tumor tissue a 'modified self-tissue', this process that may have evolved to prevent excessive purge of the $\mathrm{T}$ cell repertoire provides the potential for the development of autoimmune responses and therefore for anti-cancer therapy in adults (46).

Self-determinants are comprised of two different types: i) the dominant self-determinants, which are efficiently processed and presented and have an impact on the $\mathrm{T}$ cell repertoire by inducing thymic deletion of the auto-reactive cells; ii) the cryptic self-determinants, which are not presented in the thymus efficiently enough to ensure $\mathrm{T}$ cell tolerance during development (despite their high binding affinity for self-MHC), presumably due to incomplete processing. It has been shown that processes which result in the presentation of cryptic selfdeterminants lead to activation of those 'dormant' auto-reactive T cells that escaped thymic deletion (47).

We conclude that $\mathrm{T}$ cells specific for dominant selfdeterminants are deleted or inactivated owing to their continuous exposure to the self-antigens at the surface of APCs. In contrast, T cells specific for cryptic-self-determinants escape thymic deletion. They remain present in the periphery in a naïve stage capable of being activated if the cryptic determinant is rendered available at high doses on the surface of APCs.

\section{Dominant and cryptic determinants of the $\mathbf{p 5 3}$ protein}

The question which dominant and cryptic determinants of p53 protein induce tolerance to the tumor tissue instead of its rejection has not been adequately studied up to date. To address this issue, we have mapped p53 determinants which were presented in vitro as a series of overlapping p53 peptides to $\mathrm{T}$ cells of colorectal cancer patients. We measured the frequency of $\mathrm{T}$ cells activated by $\mathrm{p} 53$ peptides using the enzyme-linked immunospot (ELISPOT) assay. Surprisingly, both p53 determinants that activated Th2-helper cells to produce IL-10 and those that induced Th1-helper cells to secrete IFN- $\gamma$ were found. These determinants were located at either the $\mathrm{N}$ - or $\mathrm{C}$-terminal end but not in the central DNA binding domain where all hotspots for point mutations of the protein are located. The tumor stage (UICC) was important for IL-10 production in response to the $\mathrm{p} 53$ peptide sequence $\mathrm{AA}_{1-50}$. In patients with UICC stage I and II more Th2 specific lymphocytes were seen producing higher IL-10 levels in response to the peptide sequence $\mathrm{AA}_{1-50}$ than in those with stage III and IV. A decreased IL-10 expression was observed in the presence of the peptide pool $\mathrm{AA}_{291-330}$ in peripheral blood lymphocytes from patients in UICC stage III. In contrast, p53 peptide sequence $\mathrm{AA}_{331-370}$ caused an IFN- $\gamma$ expression but no correlation was found between the UICC stage and the Th1 immune response (IFN- $\gamma$ ). The level of IL-10 production seems to overweigh the IFN- $\gamma$ production, suggesting that more tolerance inducing determinants may exist within the p53 protein than those promoting rejection of p53 accumulating tumors. It also suggests that tumor-specific epitopes of tumorassociated antigens may directly influence the outcome of immunological tumor surveillance.

There is increasing evidence that during cancer development p53 becomes immunogenic. However, the precise nature of the immune response to p53 as well as its effects on tumor growth remains unknown. Although in some studies a complete tumor regression has been reported $(48,49)$, there is no satisfactory correlation between these results and clinical outcome (50). Analysis of the antigen specificity of tumorreactive $\mathrm{T}$ cells derived from cancer patients or $\mathrm{T}$ cells with in vitro reactivity against tumor-derived peptides or proteins has led to the identification of an array of potential targets for the immunotherapy of human cancers. These include protein products of genes with mutations or rearrangements unique to tumor cells, tissue-specific (but not tumor-specific) differentiation antigens, and a number of other self proteins (51). However, despite the identification of these targets, the development of effective therapeutic vaccines for cancer has been significantly limited by the lack of a means for successful vaccination against these weak, generally self-derived antigens. The failure of an anti-tumor vaccination could be explained as followed: first, the loss of antigen from the tumor, which leads to so-called tumor escape variants and second, the loss or down-regulation of specific molecules in the antigen processing pathway (52). In addition, immune responses can fail even in the presence of MHC and specific T cells, indicating that tumors can use other mechanisms to exert a certain form of immunosuppression (53-55). Our own results suggest that there could be an escape mechanism mediated by the overexpression of p53 protein. A p53 mutation leads to cytoplasmic accumulation of the protein which is then either processed by the proteosomal machinery or released into the blood- or lymphatic stream by necrotic parts of the tumor (Fig. 1). In the first case, the generated peptides are presented in an MHC class I context on the surface of a tumor cell, which may induce the p53 specific immune response accomplished by $\mathrm{CD}^{+}$cytotoxic lymphocytes. In the second case, the released p53 determinants could be captured by professional APCs such as macrophages, B-lymphocytes or dendritic cells (DCs). These cells present the appropriate epitopes in an MHC class II context to $\mathrm{CD}^{+}{ }^{+} \mathrm{T}$ helper cells. Keeping in mind that p53 has more determinants that can induce a type 2 rather than a type 1 immune response, tumors with mutations within the p53 gene must be associated with a poor prognosis. They simply might be more tolerated than tumors without a p53 gene mutation. Furthermore, it has been shown that IL-10 secreted by a range of human tumors not only can suppress the type 1 immune response but also inhibit the in vitro functional maturation of DCs. IL-10-treated DCs, instead of being immunostimulatory, can actually present antigen in a tolerogenic manner (51). The induction of the type 2 immune response by p53 determinants associated with IL-10 production, as described above, could deliver a rational explanation for the late appearance of p53 mutations in the tumor development. This may favor tumor growth as compared to tumors without p53 mutations. Assuming that the type 2 response (tolerance) overweighs the type 1 response (rejection), the anti-p53 specific immune attack against tumors with intracellular p53 accumulation must be inducible under certain conditions, for instance by 
A

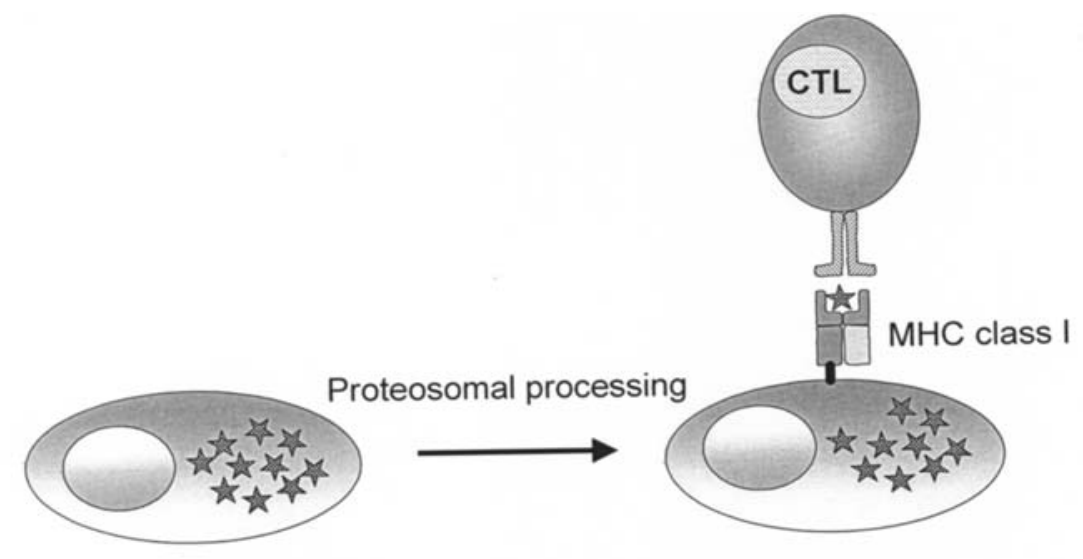

Tumor with p53 accumulation

B

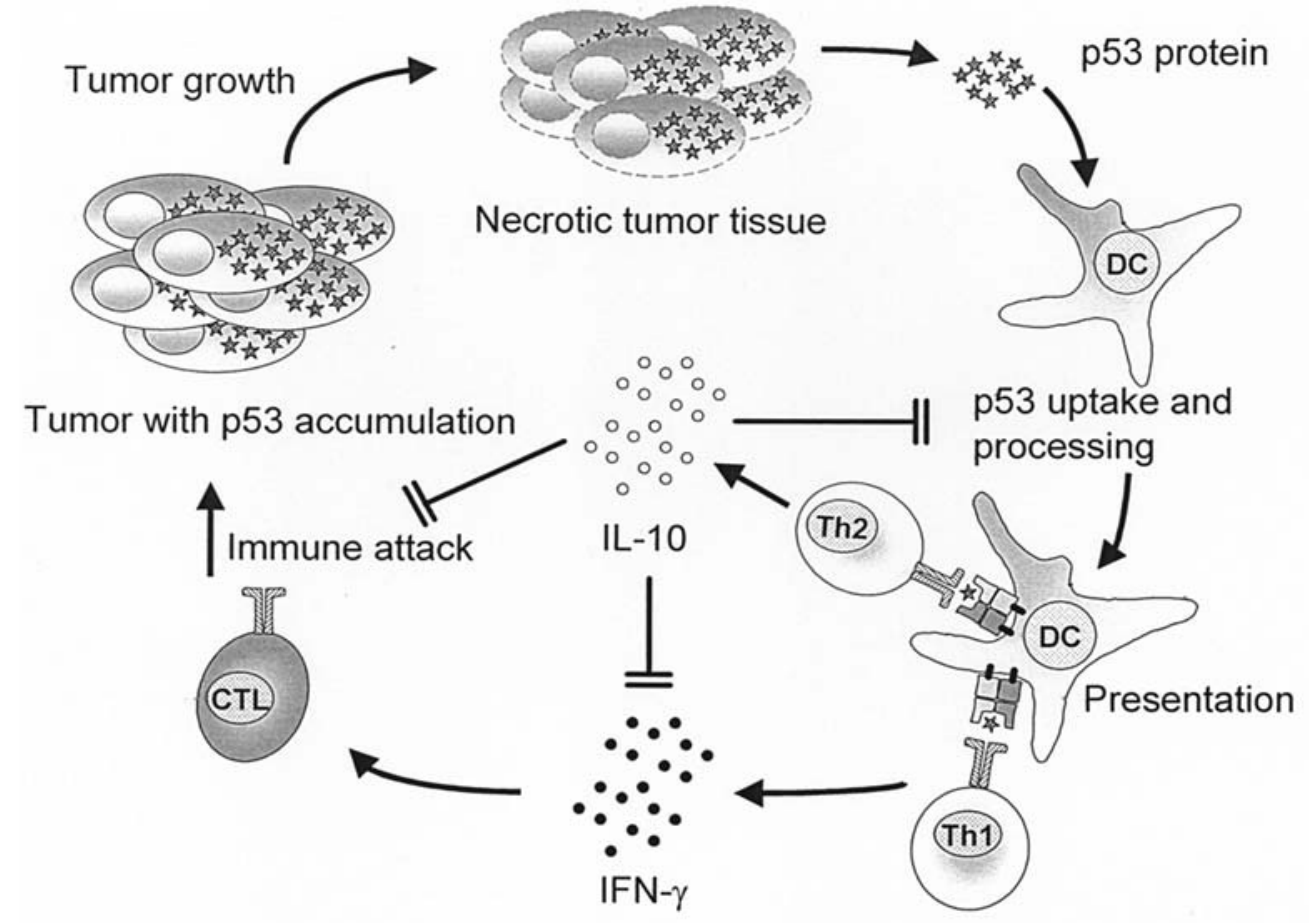

Figure 1. p53 is produced and released by tumor cells. (A), The mutated form of p53 protein is expressed in the cytosol of cancer cells at high levels. Accumulated p53 represents a reservoir of protein for proteasome processing (MHC class I restricted) and presentation on the surface of cancer cells. Recognition by $\mathrm{CD}^{+}$cytotoxic lymphocytes leads to the induction of a p53 specific immune response. (B), Great amount of accumulated p53 is released into the blood- or lymphatic stream by necrotic parts of the tumor. The released p53 determinants could be captured by professional APCs like dendritic cells (DC). They present p53 determinants on MHC class II molecules to CD4+ T helper cells of both types, types 1 and 2 . Cross-presentation on MHC class I molecules to $\mathrm{CD}^{+}$cytotoxic T cells may also occur (not shown in this figure). Both result in expression of cytokines, IL-10 (Th2) and IFN- $\gamma$ (Th1). If most p53 determinants induce a type 2 rather than type 1 immune response, IL-10 effects (decreased DC maturation, down-regulation of co-stimulatory molecules, and suppression of IFN- $\gamma$ ) would overweigh the IFN- $\gamma$ effects (clonal expansion of $\mathrm{CD}^{+}$cytotoxic $\mathrm{T}$ cells specific for the presented $\mathrm{p} 53$ epitope).

blocking the overweighing influence of the type 2 branch. This could shift the balance from tolerance to rejection and may provide an advantage in immune surveillance by exerting suppression on possible effector cells.

\section{Conclusions}

Studies suggest that one of the tumor escape mechanisms may be mediated by p53 and that the normal tolerance to p53 self-protein is not absolute and can be overcome in vivo. The questions of which p53 determinants of tumor origin are presented to $\mathrm{T}$ cells and which determinants are decisive, upon such presentation, for the resulting immune response, need to be addressed. It is demonstrated that within the p53 protein there are more tolerance-inducing determinants than those promoting rejection of p53 accumulating tumors and that the tumor-specific epitopes of the tumor-associated antigens may directly influence the outcome of immunological tumor surveillance. There are sufficient data to support the notion that cancer vaccines can induce anti-tumor immune responses in humans with cancer. How best to translate this increase in immune responsiveness to consistent and reproducible objective cancer regression or increased survival remains unclear at this time. Despite monumental advances 
in the understanding of molecular and cellular immunology, researchers have thus far been unable to translate this into clearly defined and measurable clinical benefits.

\section{Acknowledgments}

Work in the authors' laboratories is supported by a grant from Deutsche Bundesstiftung Umwelt, Germany (DBU, 16011). The authors thank the assistance of Mrs. Ulrike Faber for critical review of this manuscript.

\section{References}

1. Cho KR and Vogelstein B: Genetic alterations in the adenoma carcinoma sequence. Cancer 70: 1727-1731, 1992.

2. Ambinder RF, Robertson KD, Moore SM and Yang J: EpsteinBarr virus as a therapeutic target in Hodgkin's disease and nasopharyngeal carcinoma. Semin Cancer Biol 7: 217-226, 1996.

3. Fuchs EJ, Bedi A, Jones RJ and Hess AD: Cytotoxic T cells overcome BCR-ABL-mediated resistance to apoptosis. Cancer Res 55: 463-466, 1995.

4. Kawakami Y, Robbins PF, Wang RF and Rosenberg SA: Identification of tumor-regression antigens in melanoma. Important Adv Oncol 3-21, 1996.

5. Peace DJ, Chen W, Nelson $H$ and Cheever MA: T cell recognition of transforming proteins encoded by mutated ras proto-oncogenes. J Immunol 146: 2059-2065, 1991.

6. Van der Bruggen P, Traversari C, Chomez P, Lurquin C, De Plaen E, van den Eynde B, Knuth A and Boon T: A gene encoding an antigen recognized by cytolytic $\mathrm{T}$ lymphocytes on a human melanoma. Science 254: 1643-1647, 1991.

7. Voss RH, Lotz C, Cellary A and Theobald M: Targeting p53, hdm2, and CD19: vaccination and immunologic strategies. Bone Marrow Transplant 25 (Suppl 2): S43-S45, 2000.

8. Wu TC: Immunology of the human papilloma virus in relation to cancer. Curr Opin Immunol 6: 746-754, 1994.

9. Burnet FM: Immunological surveillance in neoplasia. Transplant Rev 7: 3-25, 1971.

10. Germain RN: Immunology. The ins and outs of antigen processing and presentation. Nature 322: 687-689, 1986.

11. Kass ES, Greiner JW, Kantor JA, Tsang KY, Guadagni F, Chen Z, Clark B, De Pascalis R, Schlom J and van Waes C: Carcinoembryonic antigen as a target for specific antitumor immunotherapy of head and neck cancer. Cancer Res 62: 5049-5057, 2002.

12. Renkvist N, Castelli C, Robbins PF and Parmiani G: A listing of human tumor antigens recognized by $\mathrm{T}$ cells. Cancer Immunol Immunother 50: 3-15, 2001.

13. Lane DP: Cancer. p53, guardian of the genome. Nature 358: 15-16, 1992.

14. Oren M, Damalas A, Gottlieb T, Michael D, Taplick J, Leal JF, Maya R, Moas M, Seger R, Taya Y and Ben-Ze'Ev A: Regulation of p53: intricate loops and delicate balances. Ann NY Acad Sci 973: 374-383, 2002.

15. Ullrich SJ, Anderson CW, Mercer WE and Appella E: The p53 tumor suppressor protein, a modulator of cell proliferation. J Biol Chem 267: 15259-15262, 1992.

16. Hollstein M, Sidransky D, Vogelstein B and Harris CC: p53 mutations in human cancers. Science 253: 49-53, 1991.

17. Coffman RL, Mocci S and O'Garra A: The stability and reversibility of Th1 and Th2 populations. Curr Top Microbiol Immunol 238: 1-12, 1999.

18. Mosmann TR and Sad S: The expanding universe of T-cell subsets: Th1, Th2 and more. Immunol Today 17: 138-146, 1996.

19. Wang $\mathrm{X}$ and Mosmann T: In vivo priming of CD4 T cells that produce interleukin (IL)-2 but not IL-4 or interferon (IFN)gamma, and can subsequently differentiate into IL-4- or IFNgamma-secreting cells. J Exp Med 194: 1069-1080, 2001.

20. Coffman RL and Reiner SL: Instruction, selection, or tampering with the odds? Science 284: 1283-1285, 1999.

21. Chene P: Inhibiting the p53-MDM2 interaction: an important target for cancer therapy. Nat Rev Cancer 3: 102-109, 2003.

22. Hernandez J, Ko A and Sherman LA: CTLA-4 blockade enhances the CTL responses to the p53 self-tumor antigen. J Immunol 166: 3908-3914, 2001.
23. Rogel A, Popliker M, Webb CG and Oren M: p53 cellular tumor antigen: analysis of mRNA levels in normal adult tissues, embryos, and tumors. Mol Cell Biol 5: 2851-2855, 1985.

24. Bargonetti J and Manfredi JJ: Multiple roles of the tumor suppressor p53. Curr Opin Oncol 14: 86-91, 2002.

25. Haupt Y, Robles AI, Prives C and Rotter V: Deconstruction of p53 functions and regulation. Oncogene 21: 8223-8231, 2002.

26. Fedoseyeva EV, Boisgerault F, Anosova NG, Wollish WS, Arlotta P, Jensen PE, Ono SJ and Benichou G: $\mathrm{CD}^{+}{ }^{+} \mathrm{T}$ cell responses to self- and mutated p53 determinants during tumorigenesis in mice. J Immunol 164: 5641-5651, 2000.

27. Chen HL and Carbone DP: p53 as a target for anti-cancer immunotherapy. Mol Med Today 3: 160-167, 1997.

28. Fujita H, Senju S, Yokomizo H, Saya H, Ogawa M, Matsushita S and Nishimura Y: Evidence that HLA class II-restricted human $\mathrm{CD}^{+} \mathrm{T}$ cells specific to $\mathrm{p} 53$ self peptides respond to $\mathrm{p} 53$ proteins of both wild and mutant forms. Eur J Immunol 28: 305-316, 1998.

29. Schlichtholz B, Legros Y, Gillet D, Gaillard C, Marty M, Lane D, Calvo $\mathrm{F}$ and Soussi T: The immune response to p53 in breast cancer patients is directed against immunodominant epitopes unrelated to the mutational hot spot. Cancer Res 52: 6380-6384, 1992.

30. Rahko E, Blanco G, Soini Y, Bloigu R and Jukkola A: A mutant TP53 gene status is associated with a poor prognosis and anthracycline-resistance in breast cancer patients. Eur J Cancer 39: 447-453, 2002.

31. Zwaveling S, Vierboom MP, Ferreira Mota SC, Hendriks JA, Ooms ME, Sutmuller RP, Franken KL, Nijman HW, Ossendorp F, van der Burg SH, Offringa R and Melief CJ: Antitumor efficacy of wild-type p53-specific CD4(+) T-helper cells. Cancer Res 62: 6187-6193, 2002.

32. Melief CJ, van der Burg SH, Toes RE, Ossendorp F and Offringa R: Effective therapeutic anticancer vaccines based on precision guiding of cytolytic T lymphocytes. Immunol Rev 188: 177-182, 2002

33. Petersen TR, Buus S, Brunak S, Nissen MH, Sherman LA and Claesson MH: Identification and design of p53-derived HLAA2-binding peptides with increased CTL immunogenicity. Scand J Immunol 53: 357-364, 2001.

34. Ohashi PS: Negative selection and autoimmunity. Curr Opin Immunol 15: 668-676, 2003.

35. Venanzi ES, Benoist C and Mathis D: Good riddance: thymocyte clonal deletion prevents autoimmunity. Curr Opin Immunol 16: 197-202, 2004.

36. Walker LS and Abbas AK: The enemy within: keeping selfreactive $T$ cells at bay in the periphery. Nat Rev Immunol 2: 11-19, 2002

37. Ignatowicz L, Kappler J and Marrack P: The repertoire of T cells shaped by a single MHC/peptide ligand. Cell 84: 521-529, 1996.

38. Tourne S, Miyazaki T, Oxenius A, Klein L, Fehr T, Kyewski B, Benoist $C$ and Mathis D: Selection of a broad repertoire of CD4 ${ }^{+}$ T cells in H-2Ma0/0 mice. Immunity 7: 187-195, 1997.

39. Van Meerwijk JP, Marguerat S, Lees RK, Germain RN, Fowlkes BJ and MacDonald HR: Quantitative impact of thymic clonal deletion on the T cell repertoire. J Exp Med 185: 377-383, 1997.

40. Liblau R, Tournier-Lasserve E, Maciazek J, Dumas G, Siffert O, Hashim G and Bach MA: T cell response to myelin basic protein epitopes in multiple sclerosis patients and healthy subjects. Eur J Immunol 21: 1391-1395, 1991.

41. Sun JB, Olsson T, Wang WZ, Xiao BG, Kostulas V, Fredrikson S, Ekre HP and Link H: Autoreactive T and B cells responding to myelin proteolipid protein in multiple sclerosis and controls. Eur J Immunol 21: 1461-1468, 1991.

42. Sakaguchi S: Naturally arising $\mathrm{CD}^{+}{ }^{+}$regulatory $\mathrm{t}$ cells for immunologic self-tolerance and negative control of immune responses. Annu Rev Immunol 22: 531-562, 2004.

43. Kappler JW, Staerz U, White J and Marrack PC: Self-tolerance eliminates T cells specific for Mls-modified products of the major histocompatibility complex. Nature 332: 35-40, 1988.

44. Kisielow P, Bluthmann H, Staerz UD, Steinmetz M and von Boehmer H: Tolerance in T-cell-receptor transgenic mice involves deletion of nonmature $\mathrm{CD}^{+} 8^{+}$thymocytes. Nature 333 : 742-746, 1988.

45. Sercarz EE, Lehmann PV, Ametani A, Benichou G, Miller A and Moudgil K: Dominance and crypticity of T cell antigenic determinants. Annu Rev Immunol 11: 729-766, 1993.

46. Moudgil KD and Sercarz EE: The self-directed T cell repertoire: its creation and activation. Rev Immunogenet 2: 26-37, 2000. 
47. Fedoseyeva EV, Tam RC, Orr PL, Garovoy MR and Benichou G: Presentation of a self-peptide for in vivo tolerance induction of $\mathrm{CD} 4^{+} \mathrm{T}$ cells is governed by a processing factor that maps to the class II region of the major histocompatibility complex locus. J Exp Med 182: 1481-1491, 1995.

48. Nestle FO, Alijagic S, Gilliet M, Sun Y, Grabbe S, Dummer R, Burg $G$ and Schadendorf D: Vaccination of melanoma patients with peptide- or tumor lysate-pulsed dendritic cells. Nat Med 4: 328-332, 1998

49. Rosenberg SA, Yang JC, Schwartzentruber DJ, Hwu P, Marincola FM, Topalian SL, Restifo NP, Dudley ME, Schwarz SL, Spiess PJ, Wunderlich JR, Parkhurst MR, Kawakami Y, Seipp CA, Einhorn JH and White DE: Immunologic and therapeutic evaluation of a synthetic peptide vaccine for the treatment of patients with metastatic melanoma. Nat Med 4: 321-327, 1998.
50. Lee KH, Wang E, Nielsen MB, Wunderlich J, Migueles S, Connors M, Steinberg SM, Rosenberg SA and Marincola FM: Increased vaccine-specific $\mathrm{T}$ cell frequency after peptide-based vaccination correlates with increased susceptibility to in vitro stimulation but does not lead to tumor regression. J Immunol 163: 6292-6300, 1999.

51. Timmerman JM and Levy R: Dendritic cell vaccines for cancer immunotherapy. Annu Rev Med 50: 507-529, 1999.

52. Algarra I, Collado A and Garrido F: Altered MHC class I antigens in tumors. Int J Clin Lab Res 27: 95-102, 1997.

53. Chouaib S: The immunotherapy of cancer and tumor escape from immune surveillance. Funct Neurol 16: 279-283, 2001.

54. Restifo NP: Not so Fas: Re-evaluating the mechanisms of immune privilege and tumor escape. Nat Med 6: 493-495, 2000.

55. Rosenberg SA: Progress in human tumour immunology and immunotherapy. Nature 411: 380-384, 2001. 